\title{
Zero-Valent Iron for the Abatement of Arsenate and Selenate from
}

\section{Flowback Water of Hydraulic Fracturing}

Yuqing Sun ${ }^{1,2}$, Season S. Chen ${ }^{2}$, Daniel C.W. Tsang, ${ }^{2,}$, Nigel J.D. Graham ${ }^{3}$, Yong Sik $\mathrm{Ok}^{4}$, Yujie Feng ${ }^{1, *}$, Xiang-Dong $\mathrm{Li}^{2}$

\section{Graphical Abstract:}

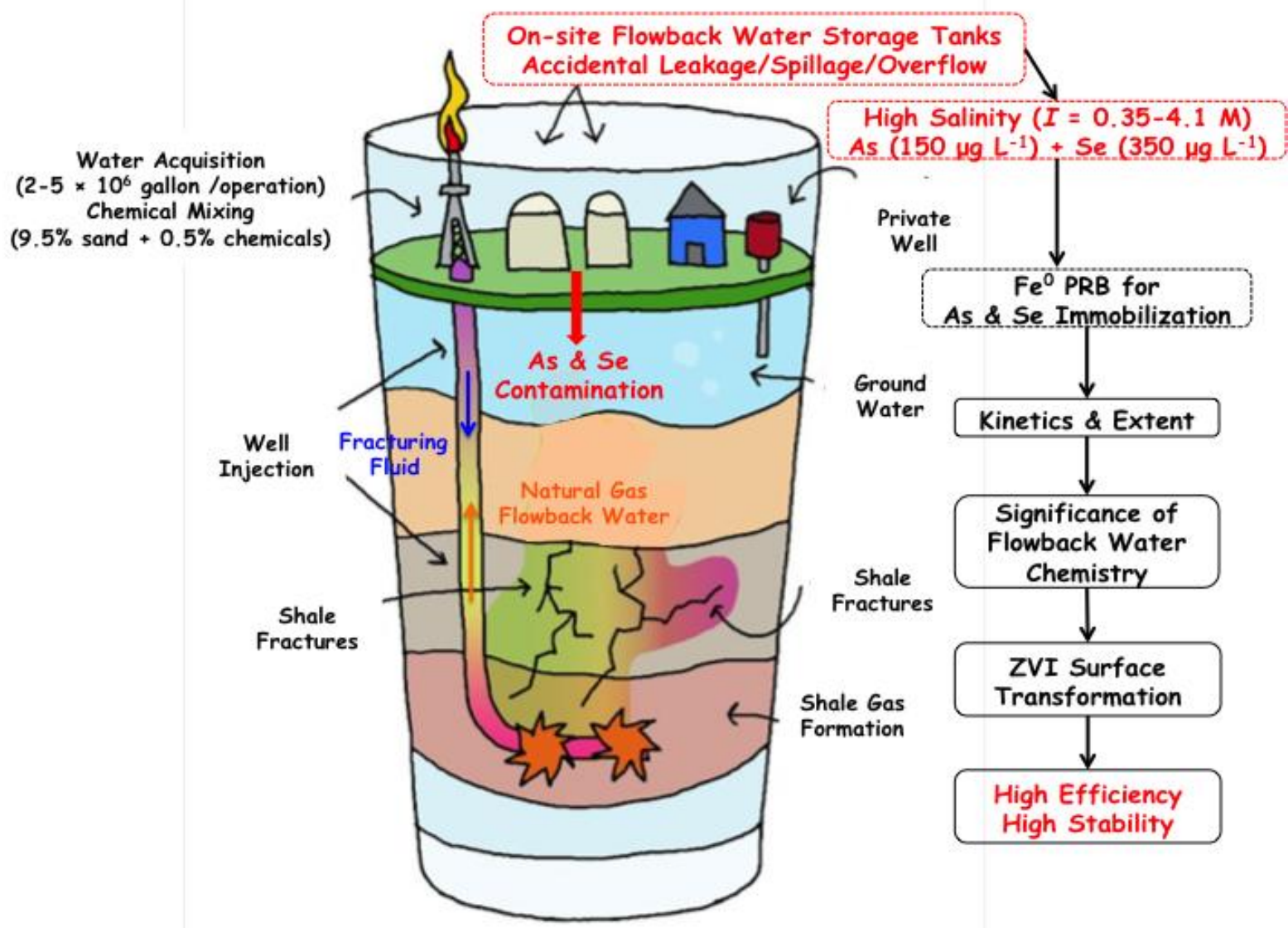




\section{Zero-Valent Iron for the Abatement of Arsenate and Selenate from Flowback}

2 Water of Hydraulic Fracturing

3

4 Yuqing Sun ${ }^{1,2}$, Season S. Chen ${ }^{2}$, Daniel C.W. Tsang ${ }^{2,}$, Nigel J.D. Graham ${ }^{3}$, Yong Sik Ok ${ }^{4}$, Yujie

$5 \quad$ Feng ${ }^{1, *}$, Xiang-Dong $\mathrm{Li}^{2}$

6

$7 \quad{ }^{1}$ State Key Laboratory of Urban Water Resource and Environment, Harbin Institute of Technology, Harbin

8 150090, China.

$9{ }^{2}$ Department of Civil and Environmental Engineering, The Hong Kong Polytechnic University, Hung Hom,

10 Kowloon, Hong Kong, China.

$11{ }^{3}$ Environmental and Water Resources Engineering, Department of Civil and Environmental Engineering,

12 Imperial College London, South Kensington, London SW7 2AZ, UK.

$13{ }^{4}$ Korea Biochar Research Center \& School of Natural Resources and Environmental Science, Kangwon

14 National University, Chuncheon 24341, Korea.

15 *Corresponding author (email: dan.tsang@polyu.edu.hk, phone: 852-2766-6072, fax: 852-2334-6389).

16 *Co-corresponding author (email: yujief@hit.edu.cn, phone: 86-451-86283068, fax: 86-451-87162150). 


\section{Abstract}

Zero-valent iron (ZVI) was tested for the removal of $150 \mu \mathrm{g} \mathrm{L}^{-1} \mathrm{As}(\mathrm{V})$ and $350 \mu \mathrm{g} \mathrm{L}^{-1} \mathrm{Se}(\mathrm{VI})$ in high-salinity (ionic strength $0.35-4.10 \mathrm{M}$ ) flowback water of hydraulic fracturing. Over $90 \%$ $\mathrm{As}(\mathrm{V})$ and $\mathrm{Se}(\mathrm{VI})$ was removed by $2.5 \mathrm{~g} \mathrm{~L}^{-1} \mathrm{ZVI}$ in Day-14 flowback water up to 96-h reaction, with the remaining concentration below the maximum contaminant level for $\mathrm{As}(\mathrm{V})$ and criterion continuous concentration for $\mathrm{Se}(\mathrm{VI})$ recommended by US EPA. The kinetics of $\mathrm{As}(\mathrm{V})$ and $\mathrm{Se}(\mathrm{VI})$ removal followed a pseudo-second-order rate expression with the observed rates of $4.51 \times 10^{-2}-4.91 \times 10^{-1}$ and $3.48 \times 10^{-2}-6.58 \times 10^{-1} \mathrm{~h}^{-1}$ (with $0.5-10 \mathrm{~g} \mathrm{~L}^{-1} \mathrm{ZVI}$ ), respectively. The results showed that $\mathrm{Se}(\mathrm{VI})$ removal significantly decreased with increasing ionic strength, while As(V) removal showed little variation. Common competing anions (nitrate, bicarbonate, silicate, and phosphate), present in shallow groundwater and stormwater, caused marginal Se(VI) desorption $(2.42 \pm 0.13 \%)$ and undetectable $\mathrm{As}(\mathrm{V})$ desorption from ZVI. The competition between $\mathrm{As}(\mathrm{V})$ and $\mathrm{Se}(\mathrm{VI})$ for ZVI removal depended on the initial molar ratio and surface sites, which occurred when the $\mathrm{Se}(\mathrm{VI})$ concentration was higher than the $\mathrm{As}(\mathrm{V})$ concentration in this study. The characterization of As(V)- and Se(VI)-loaded ZVI by X-ray diffraction and Raman analysis revealed that ZVI gradually converted to magnetite/maghemite corrosion products with lepidocrocite in flowback water over 30 days. Similar corrosion compositions were confirmed in aerobic and anaerobic conditions regardless of the molar ratio of $\mathrm{As}(\mathrm{V})$ to $\mathrm{Se}(\mathrm{VI})$. The high reactivity and stability of ZVI showed its suitability for in-situ prevention of $\mathrm{As}(\mathrm{V})$ and $\mathrm{Se}(\mathrm{VI})$ migration due to accidental leakage, spillage, or overflow of flowback water.

Keywords: zero-valent iron; hydraulic fracturing; ionic strength; arsenic; selenium; permeable reactive barrier. 


\section{Introduction}

Natural gas is a leading source of clean energy compared to coal and petroleum, and its presence in organic-rich shale formations has been identified around the world. China is believed to have one of the largest shale gas reserves, which have been estimated to be about 35 trillion $\mathrm{m}^{3}$ (Tollefson, 2013). According to the current plans (Shale Gas Development in the National 12th Five-Year Plan), shale gas will account for $8-12 \%$ of all natural gas production by 2020, as recent advances in hydraulic fracturing have made shale gas extraction economical. Typically for each operation, hydraulic fracturing requires an injection of nearly 2-5 million gallons of water with various chemical additives, known as hydraulic fracturing fluids, in order to create a network of fissures and enable gas extraction (Clark et al., 2013).

Prior to gas production, $10-70 \%$ of the hydraulic fracturing fluids is recovered as flowback water, which is enriched with shale formation constituents including chloride $\left(5,000-8,000 \mathrm{mg} \mathrm{L}^{-}\right.$ ${ }^{1}$ ), sodium (50-4,000 mg L $\left.\mathrm{L}^{-1}\right)$, calcium (500-12,000 $\left.\mathrm{mg} \mathrm{L}^{-1}\right)$, barium $\left(50-9,000 \mathrm{mg} \mathrm{L}^{-1}\right)$, magnesium (50-2,000 $\left.\mathrm{mg} \mathrm{L}^{-1}\right)$, and iron (50-160 $\left.\mathrm{mg} \mathrm{L}^{-1}\right)$. Various chemical additives used in the fracturing fluids may also contribute to the high level of total dissolved solids (up to 350,000 $\mathrm{mg}$ $\mathrm{L}^{-1}$ ). In general, the later the flowback water reaches the ground surface, the higher the ionic strength (Vengosh et al., 2013), which may influence the reactivity of the contaminants in the flowback water. In addition, toxic metals such as arsenic (As) and selenium (Se) have also been identified in flowback water in Marcellus shale, ranging from 1.5 to 151 and 2.5 to $350 \mu \mathrm{g} \mathrm{L}{ }^{-1}$ (Abualfaraj et al., 2014), respectively, which was selected as the target concentration range in this research. 
This may draw particular concerns regarding pollution by flowback water, because deep well injection is not feasible for wastewater disposal in China due to geology challenges and water shortage (Warner et al., 2013). It has been estimated that arsenic-contaminated groundwater is prevalent in areas of Northwest and Northeast China (Rodriguez-Lado et al., 2013), which probably overlap with some shale regions and arouse risk concerns. Although selenium availability plays an important role in plants and animals, livestock health may be of concern due to selenium enrichment in the underlying shales (Parnell et al., 2016). In particular, As(V) and $\mathrm{Se}(\mathrm{VI})$ would be the predominant form and susceptible to mobilization under acidic and oxidizing conditions (Goldberg et al., 2008; Phan et al., 2015), so this study investigated their removal from the synthetic flowback solution.

Zero-valent iron (ZVI) has been widely employed as a permeable reactive barrier that can form strong complexes between iron oxides and dissolved ions (Manning et al., 2002), and therefore is potentially suitable for preventing $\mathrm{As}(\mathrm{V})$ and $\mathrm{Se}(\mathrm{VI})$ migration due to accidental leakage, spillage, or overflow of flowback water. However, while there have been promising indications of the removal of $\mathrm{As}(\mathrm{V})$ and $\mathrm{Se}(\mathrm{VI})$ compounds by ZVI in low ionic strength waters, this is uncertain for flowback water where the high-salinity may interfere with metal adsorption onto the ZVI. Increasing ionic strength has been shown to enhance particle aggregation due to compressed double layers, which consequently reduce available surface sites and inhibit ZVI reactivity for contaminant removal (Sato et al., 2005). Moreover, anions such as chloride and phosphate with a lone pair of electrons could be adsorbed either specifically or non-specifically on surface iron oxide, and shift the isoelectric point of ZVI to a lower $\mathrm{pH}$ value. Therefore, the elevated chloride concentration in flowback water may reduce electrostatic attraction, or increase 
electrostatic repulsion, between ZVI and targeted contaminants, such as As(V) and $\mathrm{Se}(\mathrm{VI})$, which will be present as oxyanions in aqueous conditions (Xiao et al., 2011).

In addition, typical anions such as phosphate, silicate, bicarbonate, and nitrate in shallow ground water and stormwater may re-mobilize $\mathrm{As}(\mathrm{V})$ and $\mathrm{Se}(\mathrm{VI})$ from ZVI surfaces due to competitive adsorption (Yin et al., 2012). It has been reported that $\mathrm{As}(\mathrm{V})$ (initial concentration, $1 \mathrm{mg} \mathrm{L}^{-1}$ ) removal by $0.1 \mathrm{~g} \mathrm{~L}^{-1}$ nano-scale ZVI was reduced by $90.9 \%, 84.8 \%, 20.9 \%$ and $9.9 \%$ in the presence of $\mathrm{PO}_{4}{ }^{3-}, \mathrm{SiO}_{4}{ }^{4-}, \mathrm{HCO}_{3}{ }^{-}$, and $\mathrm{NO}_{3}{ }^{-}$, respectively (Kanel et al., 2006). Therefore, the influence of high ionic strength and competitive anions may cause concern about the effectiveness and stability of ZVI.

In order to investigate the uncertainties described above, the objectives of this study were to: (i) determine the kinetics and extent of $\mathrm{As}(\mathrm{V})$ and $\mathrm{Se}(\mathrm{VI})$ immobilization by ZVI in synthetic flowback water of different compositions; (ii) describe the interaction between flowback water chemistry (ionic strength and competing anions/cations) and $\mathrm{As}(\mathrm{V})$ and $\mathrm{Se}(\mathrm{VI})$ immobilization by ZVI; and (iii) identify the nature of the surface-formed precipitates on the As(V)- and Se(VI)treated ZVI in flowback water using spectroscopic analysis.

\section{Methods and Materials}

\subsection{ZVI and Flowback Water Constituents}

The ZVI filings (ETC-CC-1200) were obtained from Connelly GPM Inc., in which their grain size, specific surface area, and particle density were 0.25 to $2.0 \mathrm{~mm}, 1.8 \mathrm{~m}^{2} \mathrm{~g}^{-1}$, and $6.43 \mathrm{~g} \mathrm{~cm}^{-3}$, 
respectively. The chemicals used in the experiments (viz. $\mathrm{NaOH}, \mathrm{HCl}, \mathrm{KCl}, \mathrm{NaBr}, \mathrm{BaCl}_{2} \cdot 2 \mathrm{H}_{2} \mathrm{O}$, $\mathrm{CaCl}_{2} \cdot 2 \mathrm{H}_{2} \mathrm{O}, \mathrm{Fe}\left(\mathrm{NO}_{3}\right)_{3} \cdot 9 \mathrm{H}_{2} \mathrm{O}, \mathrm{SrCl}_{2} \cdot 6 \mathrm{H}_{2} \mathrm{O}, \mathrm{MgCl}_{2} \cdot 6 \mathrm{H}_{2} \mathrm{O}, \mathrm{NaCl}, \mathrm{H}_{3} \mathrm{BO}_{3}, \mathrm{Na}_{2} \mathrm{HPO}_{4}, \mathrm{Na}_{4} \mathrm{SiO}_{4}$, $\mathrm{NaHCO}_{3}, \mathrm{NaNO}_{3}$, polyacrylamide, ethylene glycol, glutaraldehyde) were reagent grade from Sigma Aldrich. Model flowback waters (corresponding to Day-1, Day-14, or Day-90, i.e., the fluids returning to the ground surface in 1,14 , or 90 days after well creation) were synthesized according to a comprehensive report of "Sampling and Analysis of Water Streams Associated with the Development of Marcellus Shale Gas" (Hayes, 2009), in which a total of 17 shale gas companies enabled the sampling of 19 locations across the Marcellus Shale Region, including 3 locations in West Virginia and 16 locations in Pennsylvania. The concentrations of major inorganic compounds in Table 1 represented the median values of the 19 locations. Three representative organic chemicals in flowback waters were also selected in this study, yet it should be noted that flowback water in the field comprised over 200 organic chemicals with concentrations and compositions dependent on proprietary fracturing fluids and shale formations. The speciation of $\mathrm{As}(\mathrm{V})$ and $\mathrm{Se}(\mathrm{VI})$ in model flowback waters were calculated using Visual MINTEQ ver. 3.0 program and shown in Table S1.

\subsection{Kinetics and Extent of As(V) and Se(VI) Removal from Flowback Water by ZVI}

Varying dosages of ZVI $\left(0.5,1,2.5,5\right.$, and $\left.10 \mathrm{~g} \mathrm{~L}^{-1}\right)$ were used for treating $50 \mathrm{~mL}$ of Day-14 flowback water with $150 \mu \mathrm{g} \mathrm{L}^{-1} \mathrm{As}(\mathrm{V})$ and/or $350 \mu \mathrm{g} \mathrm{\textrm {L } ^ { - 1 }} \mathrm{Se}(\mathrm{VI})$ (which represent the maximum concentrations reported in Marcellus flowback water) in 50-mL polypropylene copolymer centrifuge. Standard solutions of sodium arsenate and sodium selenate (Assurance grade, Spex Certiprep) were used and the initial $\mathrm{pH}$ values of the model flowback waters were adjusted by using $0.1 \mathrm{M} \mathrm{HCl}$ or $\mathrm{NaOH}$. The initial $\mathrm{pH}$ value of flowback water was in the range of 5.9-7.2, 
132 which does not affect the ZVI activity for $\mathrm{As}(\mathrm{V})$ and $\mathrm{Se}(\mathrm{VI})$ removal. The samples were shaken

133 on a rotary shaker $(30 \mathrm{rpm})$ at room temperature for $0.5,2,4,8,12,24,36,48,72$, and $96 \mathrm{~h}$, and

134 then centrifuged at $4000 \mathrm{rpm}$ for $5 \mathrm{~min}$. The supernatants were filtered through a $0.45-\mu \mathrm{m}$

135 membrane filter (Millipore) and analysed for $\mathrm{As}(\mathrm{V})$ and $\mathrm{Se}(\mathrm{VI})$ by atomic absorption

136 spectrometry with vapour generation accessory (VGA-AAS, Agilent VGA77, limits of detection

137 at $\left.1 \mu \mathrm{g} \mathrm{L}^{-1}\right)$. The selective-reduction-VGA-AAS technique was employed for measuring the 138 speciation of As(V) and Se(VI) based on Shraim et al. (1999).

140 The investigation of $\mathrm{As}(\mathrm{V})$ and $\mathrm{Se}(\mathrm{VI})$ removal was conducted with $2.5 \mathrm{~g} \mathrm{~L}^{-1} \mathrm{ZVI}$ in $50 \mathrm{~mL}$ of 141 Day-14 flowback water for $48 \mathrm{~h}$, which was adequate to reach apparent equilibrium as indicated 142 by preliminary experiments. The concentrations of $\mathrm{As}(\mathrm{V})\left(50-1500 \mu \mathrm{g} \mathrm{L}^{-1}\right)$ and $\mathrm{Se}(\mathrm{VI})(50-3500$

$143 \mu \mathrm{g} \mathrm{L}^{-1}$ ) ranging from median to 10-times maximum concentrations were based on the reported 144 values in Marcellus flowback water, and were analysed by VGA-AAS at the end of the reaction. 145 All experiments were performed in duplicate. The maximum contaminant level (MCL, US EPA) 146 of $\mathrm{As}(\mathrm{V})$ in drinking water is $10 \mu \mathrm{g} \mathrm{\textrm {L } ^ { - 1 }}$ and the criterion continuous concentration (CCC, US 147 EPA) of $\mathrm{Se}(\mathrm{VI})$ in surface water is $50 \mu \mathrm{g} \mathrm{\textrm {L } ^ { - 1 }}$. The maximum allowable concentrations of As(V) 148 and $\mathrm{Se}(\mathrm{VI})$ in surface waters (Class I to III) in China are $50 \mu \mathrm{g} \mathrm{\textrm {L } ^ { - 1 }}$ and $10 \mu \mathrm{g} \mathrm{L} \mathrm{L}^{-1}$, respectively 149 (GB3838-2002). The MCL for As(V) and CCC for Se(VI) were adopted as benchmark values in 150 this study.

\subsection{Significance of Flowback Water Chemistry for As(V) and Se(VI) Removal by ZVI}

153 The significance of ionic strength $(I)$ on $\mathrm{As}(\mathrm{V})$ and Se(VI) removal by ZVI was investigated by

154 comparing the 48-h removal of $150 \mu \mathrm{g} \mathrm{L} \mathrm{L}^{-1} \mathrm{As}(\mathrm{V})$ and/or $350 \mu \mathrm{g} \mathrm{L} \mathrm{L}^{-1} \mathrm{Se}(\mathrm{VI})$ by $2.5 \mathrm{~g} \mathrm{~L}^{-1} \mathrm{ZVI}$ in 50 
$\mathrm{mL}$ of Day-1 $(I=0.35 \mathrm{M})$, Day-14 $(I=2.49 \mathrm{M})$, and Day-90 $(I=4.10 \mathrm{M})$ flowback waters, respectively. After reaction, the concentrations of $\mathrm{As}(\mathrm{V})$ and $\mathrm{Se}(\mathrm{VI})$ in the supernatants were analysed by VGA-AAS, while the treated ZVI were recovered and gently washed with deionized water (DIW) to remove loosely entrapped $\mathrm{As}(\mathrm{V})$ and $\mathrm{Se}(\mathrm{VI})$. The As(V)-/Se-loaded ZVI was then leached for $48 \mathrm{~h}$ by each of the following: $50 \mathrm{~mL}$ of de-ionized (DI) water, background solution (BS, $10 \mathrm{mM} \mathrm{NaNO}$ ), synthetic stormwater (SSW), and competing anions present in shallow groundwater, respectively. These leaching solutions based on the literature are described as follows.

As $\mathrm{NaCl}$ was the major constituent in flowback water, sodium and chloride compounds were selected. The composition of SSW was: $\mathrm{NaCl}(5.1 \mathrm{mM}), \mathrm{CaCl}_{2}(0.75 \mathrm{mM}), \mathrm{MgCl}_{2}(0.075 \mathrm{mM})$, $\mathrm{Na}_{2} \mathrm{SO}_{4}(0.33 \mathrm{mM}), \mathrm{NaHCO}_{3}(1 \mathrm{mM}), \mathrm{NaNO}_{3}(0.072 \mathrm{mM}), \mathrm{NH}_{4} \mathrm{Cl}(0.072 \mathrm{mM})$, and $\mathrm{Na}_{2} \mathrm{HPO}_{4}$ (0.016 mM) (Mohanty et al., 2013). The concentrations of competing anions in shallow groundwater were: phosphate $(10-132 \mu \mathrm{M})$, silicate $(137-463 \mu \mathrm{M})$, and bicarbonate $(3-30 \mathrm{mM})$, representing the ranges from minimum to maximum reported values (Guo et al., 2005). Furthermore, competitive removal between maximum concentration of $\mathrm{As}(\mathrm{V})\left(150 \mu \mathrm{g} \mathrm{L} \mathrm{L}^{-1} ; 2 \mu \mathrm{M}\right)$ and median to maximum concentration of $\mathrm{Se}(\mathrm{VI})\left(53-351 \mu \mathrm{g} \mathrm{L}^{-1} ; 0.67-4.45 \mu \mathrm{M}\right)$, based on the reported Marcellus flowback water, was investigated by using ZVI $\left(2.5 \mathrm{~g} \mathrm{~L}^{-1}\right)$ in $50 \mathrm{~mL}$ of Day14 fracturing flowback water for $48 \mathrm{~h}$.

\subsection{Solid-phase Characterization of As(V)- and Se(VI)-loaded ZVI}

The ZVI was mixed at $1.0 \mathrm{~g} \mathrm{~L}^{-1}$ with $3 \mathrm{mg} \mathrm{L}^{-1} \mathrm{As}(\mathrm{V})$ (20-times maximum concentration reported in Marcellus flowback water) and 1.06, 3.16, $7 \mathrm{mg} \mathrm{L}^{-1} \mathrm{Se}(\mathrm{VI})$ (20-times maximum concentration 
reported in Marcellus flowback water) at molar ratios of 1:0.33, 1:1, 1:2.22 in Day-14 fracturing flowback water for 1-day shaking, followed by 1-min shaking by hand for another 29 days. The solutions were either used as is (i.e., aerobic) or nitrogen-purged before the experiments in order to determine the effect of redox potential on iron oxides/hydroxides formation on ZVI. The $\mathrm{As}(\mathrm{V})$ - and $\mathrm{Se}(\mathrm{VI})$-loaded ZVI samples were separated by centrifugation and freeze-dried prior to X-ray diffraction (XRD) and Raman analysis along with indigenous ZVI. The ZVI dosage and $\operatorname{As}(\mathrm{V}) / \mathrm{Se}(\mathrm{VI})$ concentrations were selected to ensure a sufficiently high surface loading of 1000 $\mathrm{mg} \mathrm{kg}^{-1} \mathrm{As}(\mathrm{V})$ and $\mathrm{Se}(\mathrm{VI})$ for subsequent spectroscopic analysis. The structure of the surface precipitates was determined by using a high-resolution powdered X-ray diffractometer (XRD, Rigaku SmartLab). The scanning degrees were from $5^{\circ}$ to $85^{\circ} 2 \theta$ with $5^{\circ} \min ^{-1}$ speed duration at $45 \mathrm{kV}$ and $200 \mathrm{~mA}$. The type of the surface precipitates formed was evaluated by using Raman spectroscope (RM 3000).

\section{Results and Discussion}

\subsection{Kinetics and Extent of $A s(V)$ and Se(VI) Removal from Flowback Water by ZVI}

The results summarized in Figure 1 show that $95.4 \pm 1.6 \% \mathrm{As}(\mathrm{V})$ (from $150 \mu \mathrm{g} \mathrm{L}^{-1}$ ) and 87.1 $\pm 0.9 \% \mathrm{Se}(\mathrm{VI})\left(\right.$ from $350 \mu \mathrm{g} \mathrm{L}^{-1}$ ) were removed after 96-h and 48-h reaction, respectively, with $2.5 \mathrm{~g} \mathrm{~L}^{-1} \mathrm{ZVI}$ in Day-14 flowback water. The solution $\mathrm{pH}$ in Day-14 flow water increased from 6.5 to 7.9 in $8 \mathrm{~h}$ and then gradually to 8.8 in $96 \mathrm{~h}$ (Figure S1), while the $\mathrm{pH}$ values similarly increased from 7.2 to 8.5 in Day-1 flowback water and from 5.9 to 8.2 in Day-90 flowback water, which was indicative of iron corrosion. The $\mathrm{E}_{\mathrm{h}}$ values varied little and ranged between 226 and $235 \mathrm{mV}$ in all individual and binary-metal solutions during the 96-h reaction. The remaining concentrations of $\mathrm{As}(\mathrm{V})$ and $\mathrm{Se}(\mathrm{VI})$ in solution were $6.9 \pm 2.4 \mu \mathrm{g} \mathrm{L}^{-1}$ and $45.2 \pm 3.1 \mu \mathrm{g}$ 
$201 \mathrm{~L}^{-1}$, respectively, which were lower than the MCL for As(V) $\left(10 \mu \mathrm{g} \mathrm{L}^{-1}\right)$ in drinking water and $202 \mathrm{CCC}$ for $\mathrm{Se}(\mathrm{VI})\left(50 \mu \mathrm{g} \mathrm{L}^{-1}\right)$ in surface water suggested by US EPA. The results demonstrated the applicability of ZVI to remove As(V) and Se(VI) from high-salinity flowback water.

The removal of $\mathrm{As}(\mathrm{V})$ and $\mathrm{Se}(\mathrm{VI})$ from flowback water by ZVI conformed to pseudo-secondorder kinetics (details can be found in the Supplementary Information and Table S2), except for

207

208

209

210 the case of $\mathrm{Se}(\mathrm{VI})$ with $0.5 \mathrm{~g} \mathrm{~L}^{-1} \mathrm{ZVI}$, which corresponded to zero-order kinetics, implying insufficient surface sites for $350 \mu \mathrm{g} \mathrm{L^{-1 }} \mathrm{Se}(\mathrm{VI})$. The observed pseudo-second-order rate coefficients $\left(k_{o b s}, \mathrm{~h}^{-1}\right)$ for $\mathrm{As}(\mathrm{V})\left(4.51 \times 10^{-2}-4.91 \times 10^{-1} \mathrm{~h}^{-1}\right)$ and $\operatorname{Se}(\mathrm{VI})\left(3.48 \times 10^{-2}-6.58 \times 10^{-1} \mathrm{~h}^{-1}\right)$ increased with increasing ZVI dosages $\left(0.5-10 \mathrm{~g} \mathrm{~L}^{-1}\right)$, and the magnitude of the increase with ZVI dose was greater for $\mathrm{Se}(\mathrm{VI})$ than $\mathrm{As}(\mathrm{V})$. This could be attributed to the different mechanisms involved in $\mathrm{As}(\mathrm{V})$ and $\mathrm{Se}(\mathrm{VI})$ removal by ZVI. Selenate could be first reduced to $\mathrm{Se}(\mathrm{IV})$ and adsorbed rapidly onto Fe oxyhydroxides, or removed in a reverse sequence (Myneni et al., 1997), while arsenate may not be reduced to As(III) after the reaction with ZVI (Farrell et al., 2001). The reduction rate of Se(VI) by ZVI could be accelerated in the presence of mineral surfaces, such as goethite, hematite, feroxyhyte and maghemite identified on the ZVI by XRD and Raman analysis (Figure S2), as Fe(II) is an important electron donor and reduced Se(IV) could be readily adsorbed onto hydrous ferric oxides (Zhang et al., 2005). Due to interference of high salinity in fracking water, no $\mathrm{As}(\mathrm{V}) / \mathrm{As}(\mathrm{III})$ and $\mathrm{Se}(\mathrm{IV}) / \mathrm{Se}(\mathrm{VI})$ was identified on $\mathrm{As}(\mathrm{V})$ - and Se(VI)-loaded ZVI solid samples in XPS tests.

Nevertheless, the surface-size normalized rate coefficients $\left(k_{s a}, \mathrm{~L} \mathrm{~m}^{-2} \mathrm{~h}^{-1}\right)$ (see SI for definition) for $\mathrm{As}(\mathrm{V})$ firstly increased from $5.01 \times 10^{-2} \mathrm{~L} \mathrm{~m}^{-2} \mathrm{~h}^{-1}$ at $0.5 \mathrm{~g} \mathrm{~L}^{-1}$ to a maximum of $9.95 \times 10^{-2} \mathrm{~L} \mathrm{~m}^{-2}$ 
$224 \mathrm{~h}^{-1}$ at $1 \mathrm{~g} \mathrm{~L}^{-1} \mathrm{ZVI}$, and then decreased with increasing ZVI dosages (1-10 $\left.\mathrm{g} \mathrm{L}^{-1}\right)$. Likewise, the $k_{s a}$ 225 for Se(VI) increased from $3.87 \times 10^{-2} \mathrm{~L} \mathrm{~m}^{-2} \mathrm{~h}^{-1}$ at $0.5 \mathrm{~g} \mathrm{~L}^{-1} \mathrm{ZVI}$ to a maximum of $5.29 \times 10^{-2} \mathrm{~L} \mathrm{~m}^{-2}$ $226 \mathrm{~h}^{-1}$ at $2.5 \mathrm{~g} \mathrm{~L}^{-1} \mathrm{ZVI}$, and then decreased with ZVI dosage (Figure 2 and Table S2). It was noted 227 that the $k_{o b s}$ and $k_{s a}$ values in this study were 2-10 times lower than those reported in previous studies for $\mathrm{As}(\mathrm{III})$ and $\mathrm{Cr}(\mathrm{VI})$ removal (Su and Puls, 2001; Liu et al., 2008). Su and Suarez (2000) noted that Se(VI) removal by amorphous iron hydroxides was dramatically decreased in 1 $\mathrm{M} \mathrm{NaCl}$ solution compared to deionized water, and the high ionic strength was found to hinder the activity of metal ions (Reddad et al., 2002). The comparatively lower rate coefficients were believed to partly result from the high-salinity solution $(I=2.49 \mathrm{M})$.

It can be seen in Figure 2 that at low ZVI dosages $\left(0.5-1 \mathrm{~g} \mathrm{~L}^{-1}\right)$, the values for As(V)- $k_{s a}$ $\left(5.01 \times 10^{-2}-9.95 \times 10^{-2} \mathrm{~L} \mathrm{~m}^{-2} \mathrm{~h}^{-1}\right)$ are greater than $\operatorname{Se}(\mathrm{VI})-k_{s a}\left(3.87 \times 10^{-2}-4.86 \times 10^{-2} \mathrm{~L} \mathrm{~m}^{-2} \mathrm{~h}^{-1}\right)$ (similar for $\mathrm{As}(\mathrm{V})-k_{o b s}$ and $\left.\mathrm{Se}(\mathrm{VI})-k_{o b s}\right)$. It has been reported that $\mathrm{As}(\mathrm{V})$ displayed a stronger adsorption affinity than $\mathrm{Se}(\mathrm{VI})$, e.g., $\mathrm{As}(\mathrm{V})>\mathrm{Se}(\mathrm{IV})>\mathrm{As}(\mathrm{III})>\mathrm{Se}(\mathrm{VI})$ on soil (Goh and Lime, 2004) and $\mathrm{As}(\mathrm{V})>\mathrm{Se}(\mathrm{IV})>\mathrm{Se}(\mathrm{VI})$ on hydrous ferric oxide (Ryden et al., 1987). In this study, the ratio of occupied site density to total site density $\left(\mathrm{ZVI}_{\text {occupied }} / \mathrm{ZVI}_{\text {total }}\right)$ was estimated to be 0.24 0.46 at $0.5-1 \mathrm{~g} \mathrm{~L}^{-1} \mathrm{ZVI}$ (Table S2; see SI for calculation). A relatively high occupation of surface sites probably rendered the difference in adsorption affinity more important. Accordingly, the kinetics and extent of $\mathrm{As}(\mathrm{V})$ removal was greater than that of $\mathrm{Se}(\mathrm{VI})$ removal by ZVI at lower dosages.

However, at higher ZVI dosages $\left(5-10 \mathrm{~g} \mathrm{~L}^{-1}\right)$ the values for $\mathrm{Se}(\mathrm{VI})-k_{s a}\left(4.85 \times 10^{-2}-3.36 \times 10^{-2} \mathrm{~L} \mathrm{~m}^{-}\right.$ $\left.{ }^{2} \mathrm{~h}^{-1}\right)$ were greater than those for As(V)- $k_{s a}\left(3.94 \times 10^{-2}-2.73 \times 10^{-2} \mathrm{~L} \mathrm{~m}^{-2} \mathrm{~h}^{-1}\right)$ (similar for Se(VI)- 
$k_{o b s}$ and $\left.\mathrm{As}(\mathrm{V})-k_{o b s}\right)$. As the $\mathrm{ZVI}_{\text {occupied }} / \mathrm{ZVI}_{\text {total }}$ was estimated to be $0.03-0.06$ only (Table S2), abundant amount of surface sites were available for $\mathrm{As}(\mathrm{V})$ and $\mathrm{Se}(\mathrm{VI})$ removal while mass transfer from bulk solution to surface sites may be the rate limiting step. According to the Fick's law of diffusion, the mass transfer rate is proportional to the product of diffusion coefficient and concentration gradient. The reported diffusion coefficient of $\mathrm{As}(\mathrm{V})$ compounds in water is in the range of $6.40 \times 10^{-6}-8.75 \times 10^{-6} \mathrm{~cm}^{2} \mathrm{~s}^{-1}$ (Tanaka et al., 2013), and that of $\mathrm{Se}(\mathrm{VI})$ compounds in water is $7.14 \times 10^{-6}-9.46 \times 10^{-6} \mathrm{~cm}^{2} \mathrm{~s}^{-1}$ (Sato et al., 1996). With similar diffusion coefficients, the mass transfer rates of $\mathrm{As}(\mathrm{V})$ and $\mathrm{Se}(\mathrm{VI})$ were therefore dependent on the concentration gradient. Since the initial concentration of $\operatorname{Se}(\mathrm{VI})\left(350 \mu \mathrm{g} \mathrm{L}{ }^{-1}, 4.45 \mu \mathrm{M}\right)$ was greater than $\mathrm{As}(\mathrm{V})(150 \mu \mathrm{g}$ $\left.\mathrm{L}^{-1}, 2 \mu \mathrm{M}\right)$, the kinetics (and therefore removal) of $\mathrm{Se}(\mathrm{VI})$ was greater than $\mathrm{As}(\mathrm{V})$. In comparison, at $2.5 \mathrm{~g} \mathrm{~L}^{-1} \mathrm{ZVI}$ dosage, the value of $\mathrm{As}(\mathrm{V})-k_{s a}\left(5.81 \times 10^{-2} \mathrm{~L} \mathrm{~m}^{-2} \mathrm{~h}^{-1}\right)$ was similar to that of $\operatorname{Se}(\mathrm{VI})-k_{s a}\left(5.29 \times 10^{-2} \mathrm{~L} \mathrm{~m}^{-2} \mathrm{~h}^{-1}\right)\left(\right.$ similar for As(V)- $k_{o b s}$ and $\left.\mathrm{Se}(\mathrm{VI})-k_{o b s}\right)$, hence this dosage was chosen for the subsequent experiments as corresponding to the lowest ZVI dosage with sufficient surface sites for $\mathrm{As}(\mathrm{V})$ and $\mathrm{Se}(\mathrm{VI})$ removal.

\subsection{Significance of Solution Chemistry of Flowback Water on As(V) and Se(VI) Removal}

The results in Figure 3 summarise the impact of solution chemistry, principally the ionic strength, of the flowback water on $\mathrm{As}(\mathrm{V})$ and $\mathrm{Se}(\mathrm{VI})$ removal. The data show that the remaining concentrations of $\mathrm{As}(\mathrm{V})$ after 48-h reaction with ZVI were $10.4 \pm 0.1 \mu \mathrm{g} \mathrm{L}{ }^{-1}$ in Day-1 $(I=0.35$ $\mathrm{M}), 15.9 \pm 1.8 \mu \mathrm{g} \mathrm{L} \mathrm{L}^{-1}$ in Day-14 $(I=2.49 \mathrm{M})$, and $11.5 \pm 0.4 \mu \mathrm{g} \mathrm{\textrm {L } ^ { - 1 }}$ in Day-90 $(I=4.10 \mathrm{M})$ flowback waters, respectively. The similar values suggest that arsenate removal was only slightly affected by ionic strength, which implied that inner-sphere surface complexes were formed with ZVI (McBride, 1997). This is consistent with observations of $\mathrm{As}(\mathrm{V})$ interactions with amorphous 
Fe oxide (Hsia et al., 1994). Evidence from previous studies using EXAFS, FTIR, and Raman spectroscopy has revealed that $\mathrm{As}(\mathrm{V})$ was adsorbed via an inner-sphere adsorption mechanism,

272 forming bi-dentate surface complexes on goethite, ferrihydrite, gibbsite, and hematite (Catalano et al., 2007). A recent study of the diffusion and reaction steps of As(V) with ZVI nanoparticles presented direct evidence that $\mathrm{As}(\mathrm{V})$ was attracted to the solid surface by electrostatic interactions and replaced a surface-bonded - $\mathrm{OH}$ group via ligand exchange (Ling and Zhang, 2014).

In contrast to $\mathrm{As}(\mathrm{V})$ removal, $\mathrm{Se}(\mathrm{VI})$ removal was significantly inhibited by the increase of ionic strength, with the remaining concentrations increasing from $21.5 \pm 0.5 \mu \mathrm{g} \mathrm{L}{ }^{-1}$ in Day-1, 45.2 \pm 3.1 $\mu \mathrm{g} \mathrm{L} \mathrm{L}^{-1}$ in Day-14, to $145 \pm 2.8 \mu \mathrm{g} \mathrm{\textrm {L } ^ { - 1 }}$ in Day-90 solutions (Figure 3). Such dependence on ionic strength corresponded to the formation of outer-sphere surface complexes (McBride, 1997). Similar results were obtained for $\mathrm{Se}(\mathrm{VI})$ adsorption on amorphous $\mathrm{Fe}$ oxide ( $\mathrm{Su}$ and Suarez, 2000), which was demonstrated to be a mono-dentate outer-sphere complex formation on goethite (Zhang and Sparks, 1990). Increasing ionic strength from deionized water to $0.1 \mathrm{M}$ $\mathrm{NaCl}$ also resulted in a rapid decrease of the rate coefficient for hexavalent chromium reduction with metallic iron (Gould, 1982), which is controlled by a surface electron transfer process. Similarly, Se(VI) removal by ZVI could be inhibited by the temporal increase of ionic strength in flowback water due to hindered electron transfer on ZVI surface. However, direct spectroscopic evidence of adsorption mechanism was not available due to the technical difficulties resulting from high-salinity interference in the As(V)- and Se(VI)-loaded ZVI samples. 
waters was listed in Table S1. In a neutral $\mathrm{pH}$ range (5.9-7.2) and aerobic condition, As(V) existed in the form of $\mathrm{H}_{2} \mathrm{AsO}_{4}{ }^{-}$and $\mathrm{HAsO}_{4}{ }^{2-}$ oxyanions. Increasing ionic strength and decreasing pH from Day-1 $(I=0.35 \mathrm{M}, \mathrm{pH}=7.2)$ to Day-90 $(I=4.0 \mathrm{M}, \mathrm{pH}=5.9)$ significantly promoted the contribution of $\mathrm{H}_{2} \mathrm{AsO}_{4}^{-}$(Day-1: 19.4\%, Day-14: 83.3\%, Day-90: 96.6\%) to the total dissolved As(V) in flowback waters. In comparison, although the predominant form of Se(VI) in flowback waters was soluble selenate $\left(\mathrm{SeO}_{4}{ }^{2-}\right)$, an increasing proportion of $\mathrm{CaSeO}_{4}$ was formed in Day-1 (29.2\%), Day-14 (97.3\%), Day-90 (99.2\%) flowback waters. Thus, the increasing formation of stable Ca-Se complex could also inhibit Se(VI) removal by ZVI in flowback waters with increasing ionic strength.

\subsection{Surface Characteristics of As(V)- and Se(VI)-loaded ZVI}

The zero valency state and crystalline structure of as-received ZVI were confirmed by XRD analysis (Figure S2a) and the Raman spectrum demonstrated that the ZVI surface was fully oxidized (Figure $\mathrm{S} 2 \mathrm{~b}$ ). The $\mathrm{Fe}(\mathrm{II}) / \mathrm{Fe}(\mathrm{III})$ and $\mathrm{Fe}(\mathrm{III})$ corrosion products on ZVI were a mixture of feroxyhyte $(\delta-\mathrm{FeOOH})$, maghemite $\left(\gamma-\mathrm{Fe}_{2} \mathrm{O}_{3}\right)$, amorphous graphite, goethite $(\alpha-\mathrm{FeOOH})$, and/or hematite $\left(\alpha-\mathrm{Fe}_{2} \mathrm{O}_{3}\right)$, which were identified with relevant information from the literature (Table S3). The XRD analysis of As(V)- and Se(VI)-loaded ZVI samples showed the peaks of magnetite/maghemite $\left(\mathrm{Fe}_{3} \mathrm{O}_{4} / \gamma-\mathrm{Fe}_{2} \mathrm{O}_{3}\right)$, lepidocrocite $(\gamma$-FeOOH$)$, and predominant $\mathrm{Fe}^{0}$ (Figure 4), which are in agreement with the previous results (Manning et al., 2002; Richmond et al., 2004). After 30-day reaction, the major component of the ZVI corrosion layers was lepidocrocite $(\gamma-\mathrm{FeOOH})$, which resulted from the oxidation of the $\mathrm{Fe}(\mathrm{II})$ formed on the corroding $\mathrm{Fe}^{0}$ surface.

Of particular note is that similar types of the iron precipitates were formed in aerobic and 
anaerobic feed solutions regardless of the various molar ratios of $\mathrm{As}(\mathrm{V})$ to $\mathrm{Se}(\mathrm{VI})$ (i.e., 1:0.33, $1: 1$, and 1:2.22), representing possible conditions in the reported flowback water. Anaerobic conditions resulted in higher XRD peak intensities and more crystalline iron oxides than aerobic conditions. The insignificant effect of dissolved oxygen and molar ratio of $\mathrm{As}(\mathrm{V})$ to $\mathrm{Se}(\mathrm{VI})$ probably suggested the presence of mature corrosion products formed on the ZVI surface during $\mathrm{As}(\mathrm{V})$ and Se(VI) removal from flowback water. Hence, the effectiveness of As(V) and Se(VI) removal by adsorption onto ZVI corrosion layers is less likely to be compromised after long-term application, while the reduction performance of ZVI may be inhibited due to hindered electron transfer through thicker shell of iron(hydro)oxides.

\subsection{Desorption of As(V) and Se(VI) from ZVI due to Competing Anions and Cations}

After 48-h reaction with ZVI in Day-14 flowback water, $1.79 \mu \mathrm{M}$ As(V) or 3.86 $\mu \mathrm{M} \mathrm{Se(VI)} \mathrm{was}$

loaded on $2.5 \mathrm{~g} \mathrm{~L}^{-1} \mathrm{ZVI}$. The results of Figure 5 show that no detectable amount of As(V) was desorbed by leaching with DIW, BS, or common competing anions in shallow groundwater (i.e., bicarbonate, silicate, and phosphate), which supported the hypothesis that As(V) may form strongly bonded inner-sphere surface complexes with ZVI. In comparison, the desorption of $\mathrm{Se}(\mathrm{VI})$ was also undetectable by leaching with DIW, BS, and $3 \mathrm{mM} \mathrm{HCO}_{3}{ }^{-}$, and there was little desorption $(0.08 \pm 0.07 \%)$ at the higher $\mathrm{HCO}_{3}{ }^{-}$concentration $(30 \mathrm{mM})$. Both $\mathrm{SiO}_{4}{ }^{4-}$ and $\mathrm{HPO}_{4}{ }^{2-}$ were relatively more effective in causing $\mathrm{Se}(\mathrm{VI})$ desorption, though the greatest desorption was only about $2.5 \%$.

The magnitude of the effect of competing anions on Se(VI) desorption was in the order phosphate $>$ silicate $>$ bicarbonate $>$ nitrate, which is consistent with the findings reported for 
$\mathrm{Se}$ (VI) desorption in a soil environment (Goh and Lim, 2004). The desorption tendency of an anion is partly attributed to its valency and the capacity to form outer- or inner- sphere complexes with ZVI (Caporale et al., 2013). Phosphate, which has a similar ionic structure as $\operatorname{As}(\mathrm{V})$, can associate with surface functional groups and form strong inner-sphere complexes with ZVI (Zhu et al., 2013), and is thus able to cause the largest Se(VI) desorption from ZVI due to competition for active surface sites. Both silicate and bicarbonate can form outer-sphere complexes with ZVI (Ramesh et al., 2007) and lower surface potential (Feng et al., 2013). Therefore, it is possible that the electrostatic repulsion increased between $\mathrm{Se}(\mathrm{VI})$ and the negatively charged surface and contributed to $\mathrm{Se}(\mathrm{VI})$ desorption. Since silicate is tetravalent and bicarbonate is monovalent, silicate could lead to larger electrostatic repulsion between $\mathrm{Se}(\mathrm{VI})$ and the ZVI surface, therefore causing more $\mathrm{Se}(\mathrm{VI})$ desorption than with bicarbonate. Nitrate is a redox-sensitive anion and could be reduced by $\mathrm{Fe}^{0}$ to form predominantly $\mathrm{NH}_{4}{ }^{+}$and smaller amounts of $\mathrm{NO}_{2}{ }^{-}$(Till et al., 1998). Desorption by nitrate in BS was not observed.

Although SSW contained $16 \mu \mathrm{M} \mathrm{HPO}_{4}{ }^{2-}$ and $1 \mathrm{mM} \mathrm{HCO}_{3}{ }^{-}$, there was much less $\mathrm{Se}(\mathrm{VI})$ desorption than the individual addition of $\mathrm{HPO}_{4}{ }^{2-}$ anion (Figure 4). It is possible that the adsorption of these two anions affected the surface charge and solution $\mathrm{pH}$ in different ways, so that the adsorption environment for the mixed anions changed compared to their individual addition (Ryden et al., 1987). Also, it is possible that the divalent cations $\left(\mathrm{Ca}^{2+}\right.$ and $\left.\mathrm{Mg}^{2+}\right)$ in the SSW neutralized some of the negative surface charges on ZVI (Tanboonchuy et al., 2013), which alleviated the electrostatic repulsion and accounted for less $\mathrm{Se}(\mathrm{VI})$ desorption in the SSW than in the presence of a single competing anion. 


\subsection{Competitive Removal of As(V) and Se(VI) by ZVI in Flowback Water}

363 The results summarized in Figure 5a show the effect of the initial Se(VI) concentration (53-350 $\left.364 \mu \mathrm{g} \mathrm{L} \mathrm{L}^{-1}, 0.67-4.45 \mu \mathrm{M}\right)$ on the removal of $\mathrm{As}(\mathrm{V})$ at a constant concentration $\left(150 \mu \mathrm{g} \mathrm{L} \mathrm{L}^{-1}\right.$ or $\left.2 \mu \mathrm{M}\right)$, 365 corresponding to a change in molar ratio of $\mathrm{As}(\mathrm{V})$ to $\mathrm{Se}(\mathrm{VI})$ from 1:0.33 to 1:2.22. When the 366 initial concentration of $\mathrm{Se}(\mathrm{VI})\left(53-158 \mu \mathrm{g} \mathrm{L} \mathrm{L}^{-1}, 0.67-2 \mu \mathrm{M}\right)$ was less than, or equal to, that of $\mathrm{As}(\mathrm{V})$, the removal of $\mathrm{As}(\mathrm{V})$ was approximately constant at $75 \%$ with $2.5 \mathrm{~g} \mathrm{~L}^{-1} \mathrm{ZVI}$ (Figure 6a).

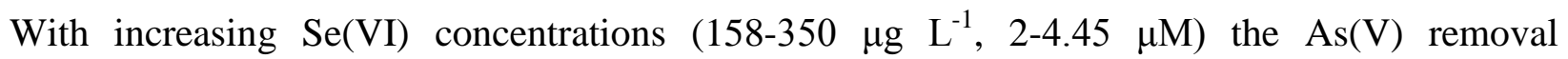
significantly reduced to $34.6 \pm 5.5 \%$ at a $\mathrm{As}(\mathrm{V}): \mathrm{Se}(\mathrm{VI})$ molar ratio of $1: 2.22$. In contrast, the $\mathrm{Se}(\mathrm{VI})$ removal increased from $54.8 \pm 9.8 \%$ to $86.7 \pm 0.3 \%$ with increasing initial $\mathrm{Se}(\mathrm{VI})$ concentration, although the greater removal did not vary substantially for $\mathrm{As}(\mathrm{V})$ to $\mathrm{Se}(\mathrm{VI})$ molar ratios $\geq 1$. These results indicate that $\mathrm{As}(\mathrm{V})$ was only sensitive to $\mathrm{Se}(\mathrm{VI})$ competition when the $\mathrm{Se}(\mathrm{VI})$ initial concentration was greater than $\mathrm{As}(\mathrm{V})$, and vice versa, under the experimental conditions.

It was also evident that the $\mathrm{Se}(\mathrm{VI})$ removal $\left(0.15 \pm 0.03\right.$ to $\left.1.54 \pm 0.01 \mu \mathrm{mol} \mathrm{g}^{-1} \mathrm{ZVI}\right)$ was approximately linear-correlated with the Se(VI) initial concentration. Also, the removal of As(V) $\left(0.60 \pm 0.01 \mu \mathrm{mol} \mathrm{g}^{-1} \mathrm{ZVI}\right)$ and $\mathrm{Se}(\mathrm{VI})\left(0.63 \pm 0.02 \mu \mathrm{mol} \mathrm{g}^{-1} \mathrm{ZVI}\right)$ was similar at $1: 1$ molar ratio. It is possible that $\mathrm{As}(\mathrm{V})$ and $\mathrm{Se}(\mathrm{VI})$ preferentially react with different sites on the ZVI when sufficient sites are available. As depicted in Figure 6b, the ZVI surface can be empirically described in terms of different sites. Fraction s1 indicates active adsorption sites, and fraction s2 represents sites that could provide electron donors for reduction by ZVI and Fe hydroxides. It is known that $\mathrm{Se}(\mathrm{VI})$ reduction by ZVI to $\mathrm{Se}(\mathrm{IV})$ is an important mechanism for $\mathrm{Se}(\mathrm{VI})$, while the competition of $\mathrm{As}(\mathrm{V})$ at these sites is unlikely as the much lower redox potential of $\mathrm{As}(\mathrm{V})$ 
reduction to $\mathrm{As}(\mathrm{III})$, compared to the $\mathrm{Se}(\mathrm{VI})$ reduction to $\mathrm{Se}(\mathrm{IV})$, makes such competition thermodynamically unfavourable (Farrell et al., 2001; Zhang et al., 2005).

Therefore, when the $\mathrm{Se}(\mathrm{VI})$ concentration was lower than that of $\mathrm{As}(\mathrm{V})$ in this case, the $\mathrm{Se}(\mathrm{VI})$ first occupied the s2 sites whereas the $\operatorname{As}(V)$ was adsorbed at the s1 sites; this was reflected by the minor impact of $\mathrm{Se}(\mathrm{VI})$ on $\mathrm{As}(\mathrm{V})$ removal. With greater $\mathrm{Se}(\mathrm{VI})$ concentrations, there was competition between $\mathrm{As}(\mathrm{V})$ and $\mathrm{Se}(\mathrm{VI})$ for the s1 sites, which is similar to the observed competition for adsorption sites of Fe hydroxides (Goh and Lim, 2004; Zhang et al., 2005). This result implies that, in addition to inner-sphere surface complexes, As(V) may also form outersphere surface complexes with ZVI that are subject to Se(VI) competition. In contrast, if present individually, the 48-h removals were consistently high (As(V): $75.8 \pm 0.2$ to $86.1 \pm 0.1 \%$; $\operatorname{Se}(\mathrm{VI})$ : 77.1 \pm 1.8 to $92.5 \pm 0.4 \%$, as indicated in Figure S3) over a wide range of As(V) $\left(250-3000 \mu \mathrm{g} \mathrm{L}^{-1}\right)$ and $\mathrm{Se}(\mathrm{VI})$ (500-7000 $\mu \mathrm{g} \mathrm{\textrm {L } ^ { - 1 } )}$ concentrations, corresponding to 20-times the maximum concentration reported in Marcellus flowback water.

\section{Conclusions}

This study has demonstrated that ZVI can sufficiently remove As(V) and Se(VI) from highsalinity flowback water. The removal of $\mathrm{Se}(\mathrm{VI})$ was more susceptible to ionic strength variations than As(V), which suggested different removal mechanisms by ZVI in flowback water. The results also showed that desorption of $\mathrm{As}(\mathrm{V})$ and $\mathrm{Se}(\mathrm{VI})$ by common competing anions present in shallow aquifer and stormwater was negligible. It is suggested that $\mathrm{Se}(\mathrm{VI})$ and $\mathrm{As}(\mathrm{V})$ preferentially occupied different surface sites on ZVI when sufficient sites were available relative to the total solute concentration, while competition for the adsorption sites occurred with 
408 increasing molar ratio of $\mathrm{Se}(\mathrm{VI})$ to $\mathrm{As}(\mathrm{V})$. The spectroscopic results revealed that ZVI corrosion 409 products formed in flowback water were less affected by the molar ratio of As(V) to Se(VI) and 410 dissolved oxygen content. Therefore, ZVI represents a potential candidate as a reactive material 411 for the in-situ prevention of $\mathrm{As}(\mathrm{V})$ and $\mathrm{Se}(\mathrm{VI})$ migration arising from the accidental leakage, 412 spillage, or overflow of flowback water.

\section{Acknowledgement}

415 The authors appreciate the financial support from the National Natural Science Foundation of 416 China (21407121), Hong Kong Research Grants Council (PolyU 538613 and 15222115), and 417 State Key Laboratory of Urban Water Resource and Environment of Harbin Institute of 418 Technology (HCK201309) for this study.

\section{References}

Abualfaraj N.; Gurian P. L.; Olson M. S. Characterization of Marcellus shale flowback water. Environmental Engineering Science. 2014, 31 (9), 514-524. competing ligands on the sorption/desorption of arsenite on/from $\mathrm{Mg}-\mathrm{Fe}$ layered double hydroxides (Mg-Fe-LDH). Chemical Engineering Journal. 2013, 225, 704-709.

Clark, C.; Burnham, A.; Harto, C. Hydraulic Fracturing and Shale Gas Production: Technology, Impacts, and Policy. Argonne National Laboratory. September, 10, 2013.

Farrell, J.; Wang, J.; O’Day, P.; Conklin, M. Electrochemical and spectroscopic study and arsenate removal from water using zerovalent iron media. Environmental Science and Technology. 2001, 35, 2026-2032. 
431 Feng, Q.; Zhang, Z.; Chen, Y.; Liu, L.; Zhang, Z.; Chen, C. Adsorption and desorption characteristics of arsenic on soils: kinetics, equilibrium, and effect of $\mathrm{Fe}(\mathrm{OH})_{3}$ colloid, $\mathrm{H}_{2} \mathrm{SiO}_{3}$ colloid and phosphate. Procedia Environmental Sciences. 2013, 18, 26-36.

Goh, K. H. and Lim, T. T. Geochemistry of inorganic arsenic and selenium in a tropical soil: effect of reaction time, $\mathrm{pH}$, and competitive anions on arsenic and selenium adsorption. Chemosphere. 2004, 55 (6), 849-859.

Goldberg, S., Hyun, S., Lee, L.S., 2008. Chemical modeling of arsenic (III, V) and selenium (V) adsorption by soils surrounding ash disposal facilities. Vadose Zone J. 7(4), 1231-1238.

Gould, J. P. The kinetics of hexavalent chromium reduction by metallic iron. Water Research. 1982, $16(6), 871-877$.

Guo, H. and Wang, Y. Geochemical Characteristics of Shallow Groundwater in Datong Basin, Northwestern China. Journal of Geochemical Exploration. 2005, 87 (3), 109-120.

Hayes, T. Sampling and Analysis of Water Streams Associated with the Development of Marcellus Shale Gas: Final report prepared for the Marcellus Shale Coalition, December 31, 2009.

Hsia, T. H.; Lo, S. L.; Lin, C. F.; Lee, D. Y. Characterization of arsenate adsorption on hydrous iron oxide using chemical and physical methods. Colloids and Surfaces A: Physicochemical and Engineering Aspects. 1994, 85 (1), 1-7.

Kanel, S. R.; Greneche, J. M.; Choi, H. Arsenic (V) removal from groundwater using nano scale zero-valent iron as a colloidal reactive barrier material. Environmental Science and Technology. 2006, 40 (6), 2045-2050.

Ling, L. and Zhang, W.X. Sequestration of arsenate in zero-valent iron nanoparticles: visualization of intraparticle reactions at angstrom resolution. Environmental Science and 
Technology Letters. 2014, 1, 305-309.

Liu, T. Z.; Tsang, D. C. W.; Lo, I. M. C. Chromium(VI) reduction kinetics by zero-valent iron in moderately hard water with humic acid: Iron dissolution and humic acid adsorption. Environmental Science and Technology. 2008, 42, 2092-2098.

Manning, B. A.; Hunt, M.; Amrhein, C.; Yarmoff, J. A. Arsenic(III) and arsenic(V) reactions with zerovalent iron corrosion products. Environmental Science and Technology. 2002, 36, $5455-5461$.

McBride, M. B. A critique of diffuse double layer models applied to colloid and surface chemistry. Clays and Clay minerals. 1997, 45 (4), 598-608.

Mohanty, S. K.; Torkelson, A. A.; Dodd, H.; Nelson, K. L.; Boehm, A. B. Engineering solution to improve the removal of fecal indicator bacteria by biofiltration systems during intermittent flow of stormwater. Environmental Science and Technology. 2013, 47 (19), 10791-10798.

Myneni, S.C.B.; Tokunaga, T.K.; Brown Jr., G.E; Abiotic selenium redox transformation in the presence of Fe(II,III) oxides. Science. 1997, (278), 1106- 1109.

Parnell J.; Brolly C.; Spinks S.; Bowden S. Selenium enrichment in Carboniferous Shales, Britain and Ireland: Problem or opportunity for shale gas extraction? Applied Geochemistry. 2016, 66, 82-87.

Ramesh, A.; Hasegawa, H.; Maki, T.; Ueda, K. Adsorption of inorganic and organic arsenic from aqueous solutions by polymeric $\mathrm{Al} / \mathrm{Fe}$ modified montmorillonite. Separation and Purification Technology. 2007, 56 (1), 90-100.

Reddad, Z.; Gerente, C.; Andres, Y.; Le Cloirec, P. Adsorption of several metal ions onto a lowcost biosorbent: Kinetic and equilibrium studies. Environmental Science and Technology. 2002, 36, 2067-2073. 
Richmond, W. R.; Loan, M.; Morton, J.; Parkinson, G. M. Arsenic removal from aqueous solution via ferrihydrite crystallization control. Environmental Science and Technology. 2004, 38, 2368-2372.

Rodriguez-Lado, L.; Sun, G.; Berg, M.; Zhang, Q.; Xue, H. B.; Zheng, Q. M.; Johnson, C. A. Groundwater arsenic contamination throughout China. Science. 2013, 341 (6148), 866-868.

Ryden, J. C.; Syers, J. K.; Tillman, R. W. Inorganic anion sorption and interactions with phosphate sorption by hydrous ferric oxide gel. Journal of Soil Science. 1987, 38 (2), 211217.

Sato, D.; Kobayashi, M.; Adachi, Y. Capture efficiency and coagulation rate of polystyrene latex particles in a laminar shear flow: Effects of ionic strength and shear rate. Colloids and Surfaces A: Physicochemical and Engineering Aspects. 2005, 266 (1), 150-154.

Sato, H.; Yui, M.; Yoshikawa, H. Ionic Diffusion Coefficients of $\mathrm{Cs}^{+}, \mathrm{Pb}^{2+}, \mathrm{Sm}^{3+}, \mathrm{Ni}^{2+}, \mathrm{SeO}_{2}^{4-}$ and $\mathrm{TcO}_{4}{ }^{-}$in Free Water Determined from Conductivity Measurements. Journal of Nuclear Science and Technology. 1996, 33 (12), 950-955.

Shraim, A., Chiswell, B., Olszowy, H. Speciation of arsenic by hydride generation-atomic absorption spectrometry (HG-AAS) in hydrochloric acid reaction medium. Talanta. 1999, 50 (5), 1109-1127.

Su, C. and Plus, R. W. Arsenate and arsenite removal by zerovalent iron: kinetics, redox transformation, and implications for in site groundwater remediation. Environmental Science and Technology. 2001, 35, 1487-1492.

Su, C. and Suarez, D. L. Selenate and selenite sorption on iron oxides an infrared and electrophoretic study. Soil Science Society of America Journal. 2000, 64 (1), 101-111.

Tanaka, M.; Takahashi, Y.; Yamaguchi, N.; Kim, K. W.; Zheng, G.; Sakamitsu, M. The difference 
of diffusion coefficients in water for arsenic compounds at various $\mathrm{pH}$ and its dominant factors implied by molecular simulations. Geochimica et Cosmochimica Acta. 2013, 105, $360-371$.

Tanboonchuy, V.; Grisdanurak, N.; Liao, C.H. Background species effect on aqueous arsenic removal by nano zero-valent iron using fractional factorial design. Journal of Hazardous Materials. 2013, 205-206, 40-46.

Till, B. A.; Weathers, L. J.; Alvarez, P. J. Fe ${ }^{0}$-supported autotrophic denitrification. Environmental Science and Technology. 1998, 32 (5), 634-639.

Tollefson, J. China slow to tap shale-gas bonanza. Nature. 2013, 494 (7437), 294.

Tsang, D.C.W., Graham, N.J.D., Lo, I.M.C. Humic acid aggregation in zero-valent iron systems and its effects on trichloroethylene removal. Chemosphere 2009, 75, 1338-1343.

United States Environmental Protection Agency (USEPA). National Primary Drinking Water Regulations. 2009, b. <http://www.epa.gov/safewater/consumer/pdf/ mcl.pdf>.

United States Environmental Protection Agency (USEPA). National Recommended Water Quality Criteria for Priority Pollutants. 2009, a. <http:// water.epa.gov/scitech/swguidance/standards/current/upload/nrwqc-2009.pdf>.

Vengosh, A.; Warner, N.; Jackson, R.; Darrah, T. The effects of shale gas exploration and hydraulic fracturing on the quality of water resources in the United States. Earth Planet Science. 2013, 7, 863-866.

Warner, N.R.; Christie, C.A.; Jackson, R.B.; Vengosh, A. Impacts of shale gas wastewater disposal on water quality in western Pennsylvania. Environmental Science \& Technology. 2013, 47, 11849-11857.

Xiao, S.; Ma, H.; Shen, M.; Wang, S.; Huang, Q.; Shi, X. Excellent copper (II) removal using 
zero-valent iron nanoparticle-immobilized hybrid electrospun polymer nanofibrous mats. Colloids and Surfaces A: Physicochemical and Engineering Aspects. 2011, 381 (1), 48-54.

Yin, W. Z.; Wu, J. H.; Li, P.; Wang, X. D.; Zhu, N. W.; Wu, P. X.; Yang, B. Experimental study of zero-valent iron induced nitrobenzene reduction in groundwater: the effects of $\mathrm{pH}$, iron dosage, oxygen and common dissolved anions. Chemical Engineering. 2012, 184, 198-204.

Zhang, P. and Sparks, D. L. Kinetics of selenate and selenite adsorption/desorption at the goethite/water interface. Environmental Science and Technology. 1990, 24 (12), 1848-1856.

Zhang, Y.Q.; Amrhein, C.; Frankenberger Jr., W.T. Effect of arsenate and molybdate on removal of selenate from an aqueous solution by zero-valent iron. Science of the Total Environment. 2005, 350, 1-11.

Zhu, J.; Pigna, M.; Cozzolino, V.; Caporale, A. G.; Violante, A. Higher sorption of arsenate versus arsenite on amorphous Al-oxide, effect of ligands. Environmental Chemistry Letters. 2013, $11(3), 289-294$. 

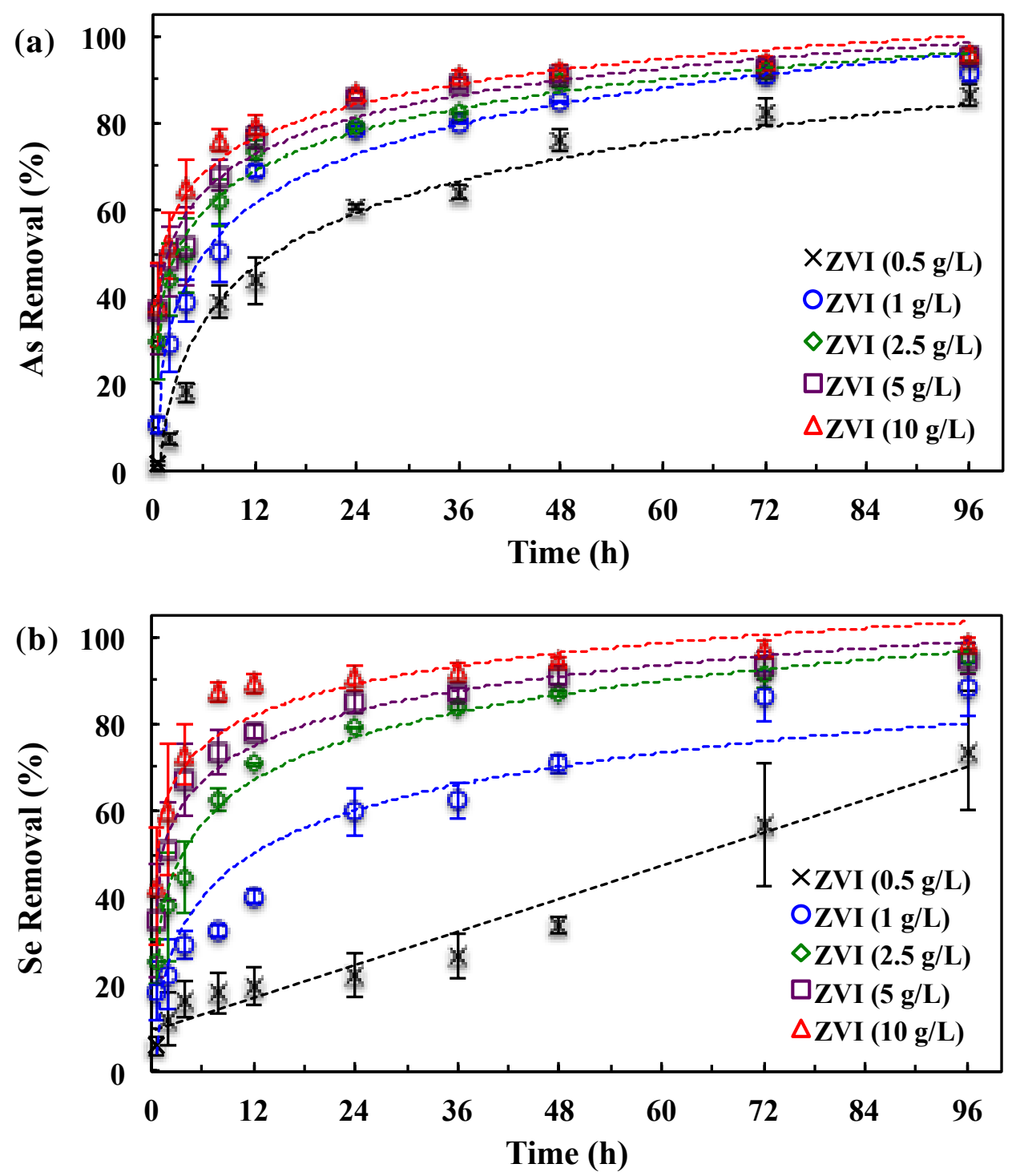

Figure 1. Time-dependent removal of (a) $\mathrm{As}(\mathrm{V})\left(150 \mu \mathrm{g} \mathrm{L} \mathrm{L}^{-1}\right)$ and (b) $\mathrm{Se}(\mathrm{VI})\left(350 \mu \mathrm{g} \mathrm{L}^{-1}\right)$ from Day-14 flowback water at $\mathrm{pH} 6.5$ by $0.5-10 \mathrm{~g} \mathrm{~L}^{-1} \mathrm{ZVI}$. 


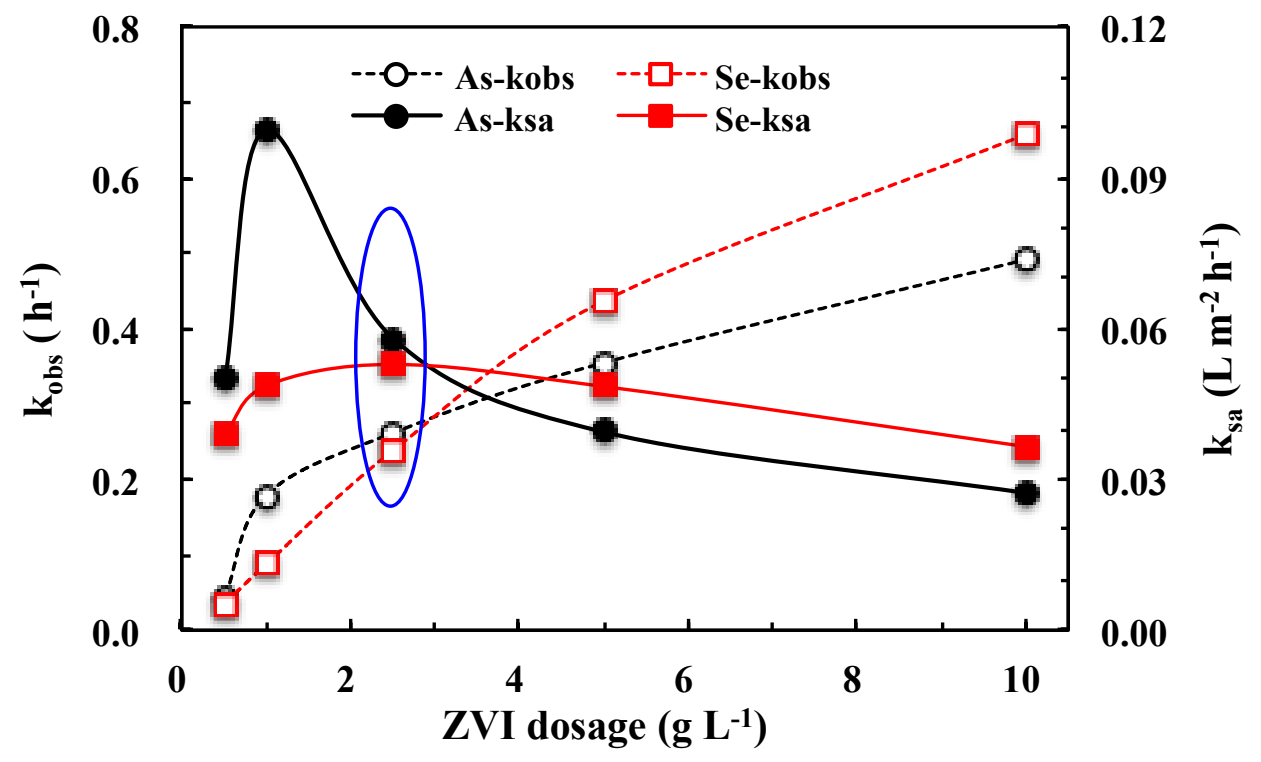

Figure 2. Pseudo-second-order rates $\left(k_{o b s}\right.$ and $\left.k_{s a}\right)$ for removal of $\mathrm{As}(\mathrm{V})\left(150 \mu \mathrm{g} \mathrm{L}{ }^{-1}\right)$ and $\mathrm{Se}(\mathrm{VI})\left(350 \mu \mathrm{g} \mathrm{L}^{-1}\right)$ from Day-14 flowback water at $\mathrm{pH} 6.5$ by $0.5-10 \mathrm{~g} \mathrm{~L}^{-1} \mathrm{ZVI}$. 

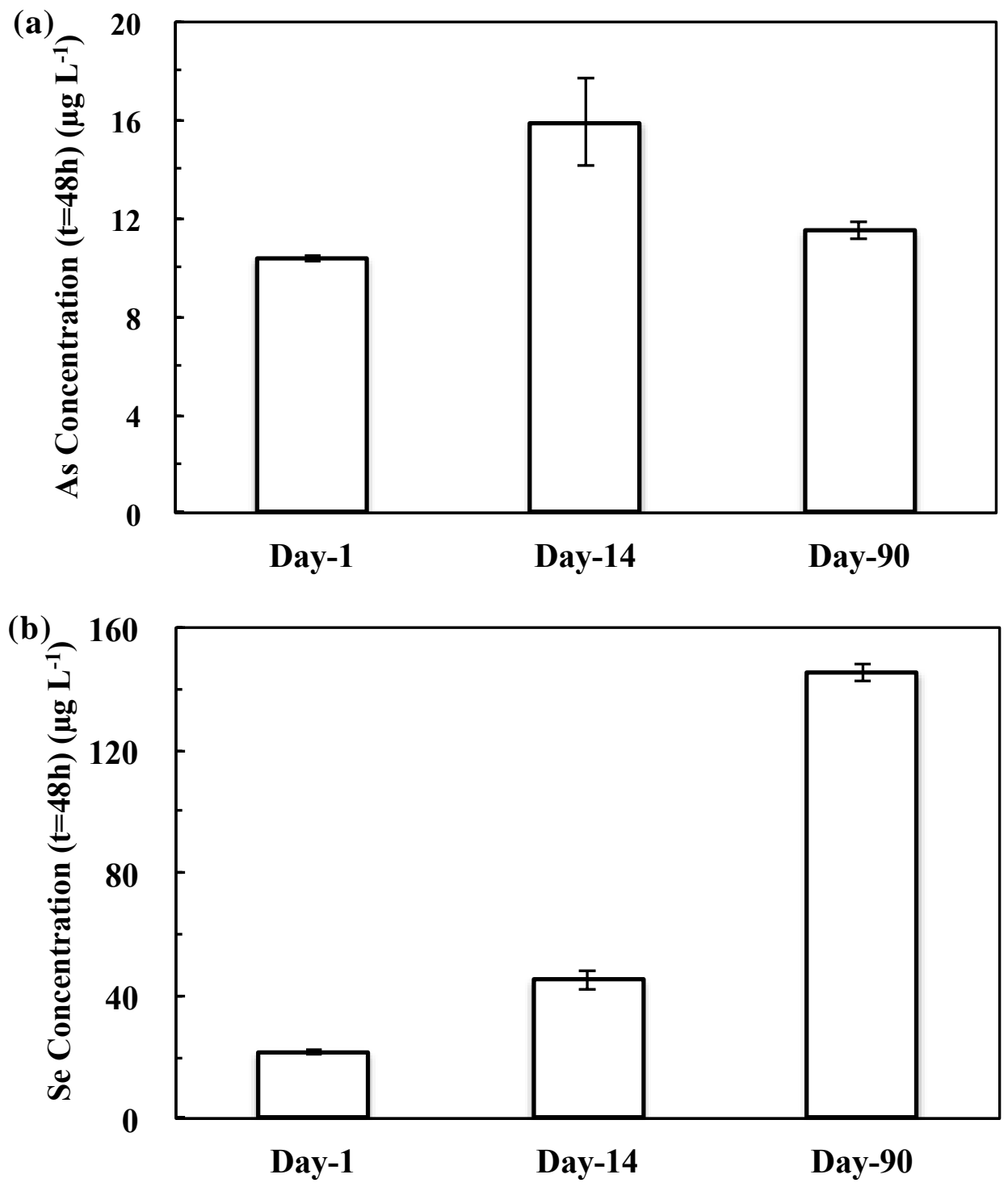

Figure 3. Significance of ionic strength on the 48-h removal of (a) As(V) $\left(150 \mu \mathrm{g} \mathrm{L}^{-1}\right)$ and (b) $\mathrm{Se}(\mathrm{VI})\left(350 \mu \mathrm{g} \mathrm{L}^{-1}\right)$ from Day-1 $(I=0.35 \mathrm{M})$, Day-14 $(I=2.49 \mathrm{M})$, Day-90 $(I=$ $4.10 \mathrm{M}$ ) flowback water at $\mathrm{pH} 6.5$ by $2.5 \mathrm{~g} \mathrm{~L}^{-1} \mathrm{ZVI}$. 

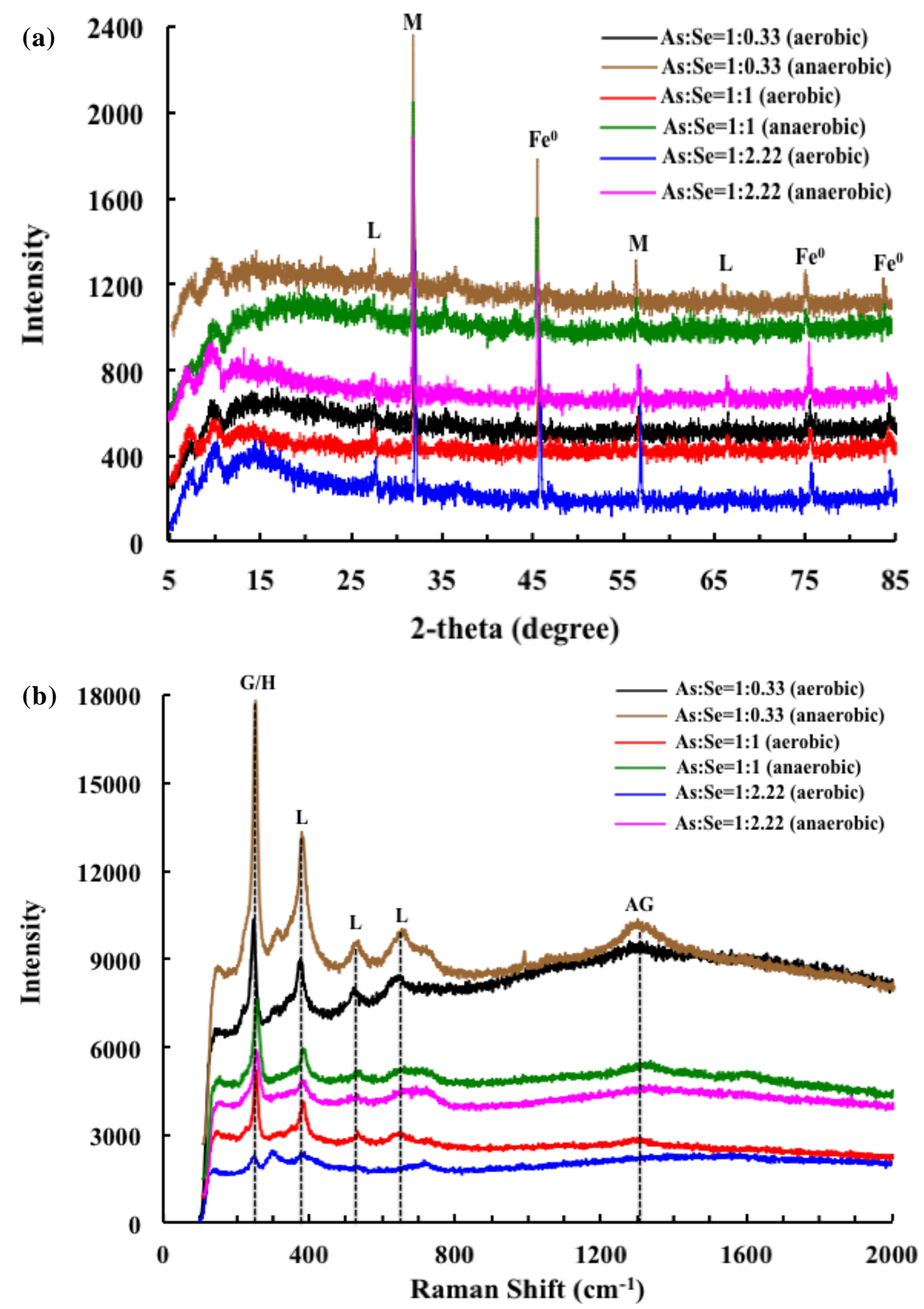

Figure 4. XRD (a) and Raman (b) analysis of As(V)- and Se(VI)-loaded ZVI in Day-14 flowback water for 30 days at different molar ratios under aerobic and anaerobic conditions (remarks: major peaks correspond to magnetite/maghemite $\left(\mathrm{Fe}_{3} \mathrm{O}_{4} / \gamma-\mathrm{Fe}_{2} \mathrm{O}_{3}\right)$ $(\mathrm{M})$, lepidocrocite $(\gamma-\mathrm{FeOOH})(\mathrm{L})$, goethite/hematite $\left(\alpha-\mathrm{FeOOH} / \alpha-\mathrm{Fe}_{2} \mathrm{O}_{3}\right)(\mathrm{G} / \mathrm{H})$, amorphous graphite $(\mathrm{AG})$, and $\left.\mathrm{Fe}^{0}\right)$. 


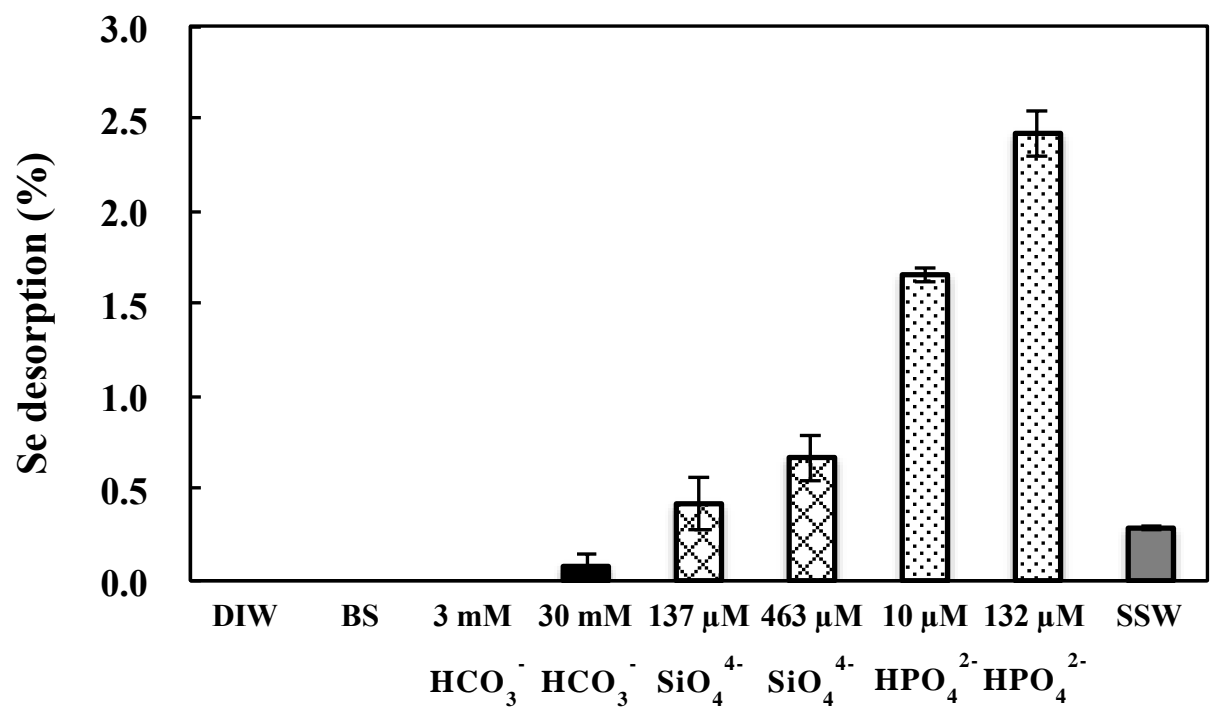

Figure 5. Desorption of $\mathrm{Se}(\mathrm{VI})$ and $\mathrm{As}(\mathrm{V})$ by deionized water (DIW), background solution (BS), competitive anions, and synthetic stormwater (SSW) after 48-h removal by ZVI (remarks: $150 \mu \mathrm{g} \mathrm{L}{ }^{-1}(2 \mu \mathrm{M}) \mathrm{As}(\mathrm{V})$ or $350 \mu \mathrm{g} \mathrm{L}^{-1}(4.45 \mu \mathrm{M}) \mathrm{Se}(\mathrm{VI})$ in Day-14 flowback water at $\mathrm{pH} 6.5$ was first removed by $2.5 \mathrm{~g} \mathrm{~L}^{-1} \mathrm{ZVI}$; in all desorption experiments, As(V) was undetectable in the leaching solutions). 

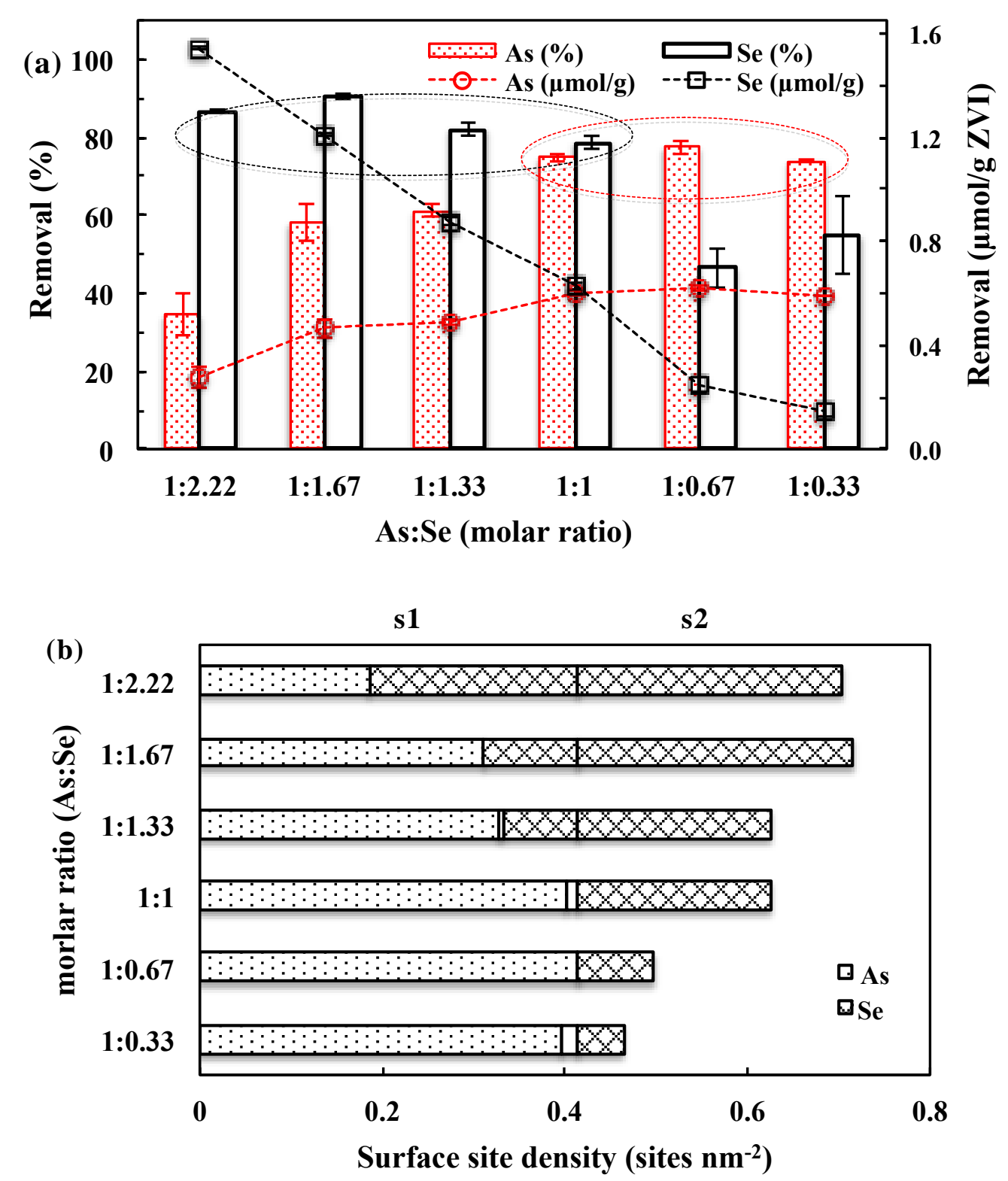

Figure 6. Competition between $\mathrm{As}(\mathrm{V})\left(150 \mu \mathrm{g} \mathrm{L}^{-1}\right.$, or $\left.2 \mu \mathrm{M}\right)$ and $\mathrm{Se}(\mathrm{VI})\left(53-351 \mu \mathrm{g} \mathrm{L}^{-1}\right.$, or $0.67-4.45 \mu \mathrm{M})$ at varying molar ratio in Day-14 flowback water at $\mathrm{pH} 6.5$ by $2.5 \mathrm{~g} \mathrm{~L}^{-1}$ ZVI: (a) 48-h removal and (b) occupied site density (remarks: fraction s1 indicates adsorption sites whereas fraction $\mathrm{s} 2$ indicates reduction sites). 
Table 1. Chemical compositions of synthetic fracturing flowback water

\begin{tabular}{clccc}
\hline Constituents & Units & Day 1 & Day 14 & Day 90 \\
\hline $\mathrm{KCl}$ & $\mathrm{g} \mathrm{L}^{-1}$ & 0 & 0 & 31.9 \\
$\mathrm{NaBr}$ & $\mathrm{g} \mathrm{L}^{-1}$ & 0.113 & 0.911 & 1.51 \\
$\mathrm{BaCl}_{2} \cdot 2 \mathrm{H}_{2} \mathrm{O}$ & $\mathrm{g} \mathrm{L}^{-1}$ & 0.689 & 3.26 & 3.80 \\
$\mathrm{CaCl}_{2} \cdot 2 \mathrm{H}_{2} \mathrm{O}$ & $\mathrm{g} \mathrm{L}^{-1}$ & 2.48 & 40.6 & 67.8 \\
$\mathrm{Fe}\left(\mathrm{NO}_{3}\right)_{3} \cdot 9 \mathrm{H}_{2} \mathrm{O}$ & $\mathrm{g} \mathrm{L}^{-1}$ & 0.140 & 0.540 & 0.844 \\
$\mathrm{MgCl}_{2} \cdot 6 \mathrm{H}_{2} \mathrm{O}$ & $\mathrm{g} \mathrm{L}^{-1}$ & 1.02 & 7.85 & 14.2 \\
$\mathrm{SrCl}_{2} \cdot 6 \mathrm{H}_{2} \mathrm{O}$ & $\mathrm{g} \mathrm{L}^{-1}$ & 0.476 & 10.1 & 9.56 \\
$\mathrm{NaCl}$ & $\mathrm{g} \mathrm{L}^{-1}$ & 15.2 & 80.7 & 111 \\
$\mathrm{H}_{3} \mathrm{BO}_{3}$ & $\mathrm{~g} \mathrm{~L}^{-1}$ & 0.046 & 0.094 & 0.102 \\
polyacrylamide & $\mathrm{g} \mathrm{L}^{-1}$ & 0.8 & 0.8 & 0.8 \\
ethylene glycol & $\mathrm{g} \mathrm{L}^{-1}$ & 0.43 & 0.43 & 0.43 \\
glutaraldehyde & $\mathrm{g} \mathrm{L}^{-1}$ & 0.1 & 0.1 & 0.1 \\
\hline $\mathrm{pH}$ & - & 7.2 & 6.5 & 5.9 \\
Ionic strength & $\mathrm{M}$ & 0.35 & 2.49 & 4.10 \\
\hline
\end{tabular}

